Cómo citar este trabajo: Urkidi Azkarraga, L. (2018). Espacios agrarios y justicia de género: un caso de estudio en el País Vasco. Boletín de la Asociación de Geógrafos Españoles, 78, 329-391. doi: http://dx.doi.org/10.21138/bage.2718

\title{
Espacios agrarios y justicia de género: un caso de estudio en el País Vasco
}

Agrarian spaces and gender justice:

a case study in the Basque Country

\author{
Leire Urkidi Azkarraga \\ Leire.urkidi@ehu.eus \\ Departamento de Geografía, Prehistoria y Arqueología \\ Universidad del País Vasco (España)
}

\section{Resumen}

El artículo explora la intersección entre espacio agrario y feminismo, a partir de un caso de estudio en Usurbil (País Vasco). El objetivo es visibilizar y analizar las experiencias, desigualdades e identidades de la mujer agricultora -agente social ausente en nuestras narrativas- en el contexto del Norte Global. Se analizan las múltiples injusticias de género en relación a la división sexual del trabajo, las relaciones de poder, la participación y el reconocimiento (ausente/estereotipado), para concluir con las especificidades de estas injusticias para el espacio agrario y para el caso vasco.

Palabras clave: justicia de género; geografía agraria; geografía del género; País Vasco; feminismo.

\begin{abstract}
This paper explores the intersection between feminism and agrarian space, following a case study developed in Usurbil (Basque Country). The main objective is to analyze and make visible the experiences, inequities and identities of women farmers in the context of the Global North -an absent social agent in our narratives. It analyses the multiple gender injustices in relation to the sexual division of labor, power relationships, participation and recognition (absent/stereotyped) and concludes with the specificities of these injustices for the agrarian context and the Basque case.
\end{abstract}

Key words: gender justice; agricultural geography; gender geography; Basque country; feminism. 


\section{Introducción}

El presente artículo analiza la intersección entre espacios agrarios y feminismo, a partir del análisis de las experiencias cotidianas de las mujeres agricultoras vascas, en un caso de estudio, y de las múltiples dimensiones de su discriminación. El complejo agroalimentario actual simboliza lo injusto e insostenible del sistema socio-económico; un sistema centrado en la producción y que obvia y minusvalora el mantenimiento y el cuidado digno de la vida humana (Herrero, 2011). Las actividades agrogranaderas, básicas para la provisión de alimentos y sostenimiento material de la sociedad, se han visto empujadas a dos extremos insostenibles: la intensividad productivista de una agricultura industrializada y mercantilizada o la marginación de toda aquella actividad no competitiva. La marginación del campesinado en España y el País Vasco desde los años 60 tiene su máxima expresión en las mujeres agricultoras por su pertenencia a espacios doble o triplemente discriminados (espacios agrario y rural y esfera feminizada). La mujer agricultora ha estado ausente en la narración historiográfica y en la generación de discurso tanto a nivel cotidiano como público. Como invita de Sousa Santos (2006, p. 26), el objetivo central de esta investigación es hacer presente lo ausente; en este caso, la experiencia de las mujeres agricultoras y los diferentes aspectos de su marginación.

El feminismo aporta claves importantes frente a esta situación, a nivel de visibilizar y combatir las injusticias sociales y de género y a nivel de conceptualizar y proponer otras maneras de organización económica centradas en el mantenimiento de la vida. El objetivo del prisma feminista no es simplemente sumar o agregar a las mujeres en el análisis (Harding, 1988, p. 10), sino que el conocimiento sobre su situación, experiencias y resistencias nos ayude a reflexionar y reconceptualizar el sistema social y económico, sus puntos de fuga y las posibilidades de su transformación.

Este artículo se centra en una investigación cualitativa basada en entrevistas en profundidad con mujeres baserritarras (campesinas o dedicadas a la actividad agraria) realizadas en Usurbil (Gipuzkoa) en 2014. Aunque la reflexión que aquí se presenta incluye referencias a investigaciones de diferentes regiones del Norte Global (Estados Unidos, Europa, España), parece importante partir del estudio de un espacio concreto. Como señala Razavi (2003, pp. 29-30), la interfase entre la tierra y el género es específica a nivel contextual y no se puede abordar adecuadamente solo a partir de prescripciones globales para-todo-propósito. En este sentido, la mujer agricultora vasca ha sufrido una triple ausencia durante décadas por razón de género, geografía (la dispersión del mundo rural vasco y la minusvaloración de lo agrario) y cultura (especialmente durante la dictadura de Franco pero también antes y después). Precisamente, la teoría feminista interseccional sugiere que el género, la etnia, la clase, la sexualidad o la territorialidad, entre otros ejes, forman sistemas de poder mutuamente constitutivos que marcan la vida de las personas (Collins, 2006 en Trauger et 
al., 2008, p. 433). También para las mujeres agricultoras vascas, sus múltiples lugares de identidad configuran su relación con la agricultura y la manera en que son percibidas y autopercibidas (Trauger et al., 2008, pp. 433-434).

Partiendo de las aportaciones de la Geografía del Género, este trabajo se centra en las diferentes injusticias señaladas por las teóricas de la Justicia de Género. Fraser (1996) explicita las diversas dimensiones interrelacionadas que configuran las situaciones de (in)justicia: distribución de bienes socio-económicos, reconocimiento y participación. En este sentido, el artículo analiza la división sexual del trabajo y otras inequidades en el ámbito agrario (vinculado a la dimensión distributiva), las identidades, estereotipos y relaciones de poder (vinculado al eje del reconocimiento) y la participación pública de las mujeres agricultoras (dimensión participativa). Dada la gran disminución de las actividades agro-ganaderas en Usurbil, la mayoría de testimonios recogidos hacen referencia al periodo 1950-1980, cuando las mujeres entrevistadas identifican el caserío como activo a nivel productivo. El caso de las mujeres de Usurbil ejemplifica la coexistencia de los tres tipos de injusticia de género en el espacio agrario y muestra las especificidades de estas injusticias tanto para el ámbito agrario como para la realidad vasca.

Tras esta introducción, en el artículo se expone el marco teórico, la metodología de investigación y una síntesis del contexto agrario actual. Después, se aborda el análisis del caso de Usurbil en relación con otras investigaciones a partir de las diferentes dimensiones de la justicia de género, para terminar con las conclusiones y unas breves reflexiones sobre las posibles vías de transformación.

\section{Marco teórico}

Una de las principales características de los estudios de género y feministas es que han propiciado enfoques interdisciplinares, articulando aportaciones de diferentes áreas de conocimiento de las ciencias sociales y humanas y, en algunos casos, bio-físicas (Bonán \& Guzmán, 2007, p. 1). Según Estela Serret (1999, pp. 22-23), esto se debe a la misma génesis de la teoría feminista que nace como una crítica a las bases epistémicas y metodológicas de las diferentes disciplinas científicas desde la llustración. La reflexión feminista surge como una puesta en cuestión de los supuestos explícitos o implícitos que las diferentes disciplinas realizan sobre las mujeres y las relaciones de género (Serret, 1999, pp. 22-23). Sin embargo, según esta autora, sí podemos decir que la reflexión feminista es una teoría en sí misma porque supone una reconfiguración epistémica y hermenéutica (interpreta y transforma el sentido de lo dicho) y porque tiene un objeto de estudio distintivo; sin embargo, debemos tomarla como una teoría interdisciplinaria radical porque atraviesa las disciplinas no para unificarlas sino para mostrar su interior (Serret, 1999, pp. 23-24). 
Por tanto, este trabajo abraza este enfoque y toma conocimientos de diferentes disciplinas. Una de las que más ha trabajado la intersección entre agricultura y feminismo ha sido la Geografía Feminista o de Género. Esto se debe a que uno de los principales ámbitos de estudio de la Geografía es el espacio y el territorio y, en el caso de la Geografía Rural, el espacio agrario. En este sentido, Little et al. (1988, p. 2) definen así la Geografía del Género:

Es la geografía que examina las formas en que los procesos socioeconómicos, políticos y ambientales crean, reproducen y transforman no sólo los lugares donde vivimos sino también las relaciones sociales entre los hombres y las mujeres, y a su vez, estudia cómo las relaciones de género tienen un impacto en dichos procesos y en sus manifestaciones en el espacio y en el entorno (Little et al., 1988, p. 2, traducción de Baylina \& Salamaña, 2006, p. 100).

Las investigaciones de la Geografía del Género, en su vertiente rural, han estudiado la división sexual del trabajo y las relaciones de poder en la explotación agraria, la unidad familiar y la comunidad rural, así como la relación de la mujer con la naturaleza como temas prioritarios (Baylina y Salamaña, 2006:101). Muchos estudios deconstruyen la idealización del medio rural como espacio de cohesión social para mostrar las desigualdades y la multiplicidad de identidades, a veces conflictivas y a veces transformadoras, que las conforman.

De manera relacionada, aunque partiendo de un contexto más urbano, la Justicia de Género ha emergido desde hace varias décadas como una línea de pensamiento que permite analizar, de manera interdisciplinar, múltiples discriminaciones desde un prisma feminista. La relevancia de esta línea de estudio y reivindicación, así como las diferentes dimensiones que señala, han sido de gran utilidad conceptual y analítica para el desarrollo de esta investigación.

En 1990, Iris Young publicó el libro Justice and the Politics of Difference, desarrollando una crítica a la justicia social distributiva desde una posición que tenía en cuenta la diferencia cultural. En este libro, Young critica la centralidad economicista de la eminente obra de John Rawls Theory of Justice. Si Rawls (1971) equipara justicia con equidad (distribución igualitaria de los bienes económicos y sociales) y desarrolla una teoría de corte liberal basada en la igualdad de oportunidades, Young argumenta que, aunque la distribución es crucial para alcanzar la justicia, sería un error reducir la justicia social a la equidad. Para ella (1990, pp. 71-72), no solo es importante la maldistribución sino los procesos que construyen esa maldistribución: los procesos políticos, la capacidad/poder de participación de los diferentes agentes, o el reconocimiento de las diferentes necesidades y características de los agentes (no solo a nivel individual sino también colectivo). Esta última es una de las claves de las políticas de la diferencia.

Young (1990, pp. 71-72) señala que la injusticia se refiere a dos formas de incapacitación principales: la opresión y la dominación. Y subraya que la estructura social viene marcada por los 
procesos de socialización que vivencia cada individuo y que determinan su identificación de género, clase, etnia, etc. (Young, 1990, p. 79). Young "pone el acento en la vivencia de la sujeción como aquella que requiere ser reconocida en aras de una construcción colectiva sobre el sentido de lo justo y de lo público" (Palacio, 2013, p. 82). Sólo así podrá protegerse la diferencia política y social, imposibilitando una aplicación limitada de la alteridad.

Nancy Fraser (1996), por su parte, busca una perspectiva más normativa, y parte de un esquema bifocal de la justicia donde recupera las cuestiones redistributivas y resalta la relevancia del reconocimiento y la cultura. Ante la pregunta de "¿equidad o política de identidad?" que en muchos casos encontramos en el debate feminista, Fraser (2008, p. 84) no reconoce la antítesis y promulga una integración, aunque reconoce los dilemas concretos que supone.

Fraser (2008, p. 91) defiende que el género es una diferenciación social bidimensional: "no es una simple clase ni un mero grupo de estatus, sino una categoría híbrida enraizada al mismo tiempo en la estructura económica y en el orden de estatus de la sociedad". El género organiza la estructura económica de la sociedad capitalista: organiza la división entre trabajo retribuido o productivo y trabajo no retribuido o reproductivo, asignando este último a las mujeres, y organiza la división, dentro del trabajo pagado, entre las ocupaciones de salarios altos y predominio masculino y las ocupaciones de cuidados, salarios bajos y predominio femenino (Fraser, 2008, p. 92). "El resultado es una estructura económica que genera formas de injusticia distributiva, específicas de género" (Fraser, 2008, p. 92).

Pero, además, el género es una diferenciación de estatus. El androcentrismo es un patrón institucionalizado de valor cultural que privilegia los rasgos asociados a lo masculino y devalúa lo vinculado a lo femenino (Fraser, 2008, p. 92). Por ello, las mujeres sufren formas específicas de subordinación: agresiones sexuales, representaciones estereotipadas y cosificadoras, menosprecio en la vida cotidiana, exclusión en las esferas públicas, o negación de los derechos plenos. Estos daños son injusticias de reconocimiento (Fraser, 2008, p. 92).

Por tanto, para luchar contra las injusticias de género, es necesario abolir el género como clase económica y abolir el androcentrismo. Y para articular estos dos ideales, Fraser propone la noción de paridad participativa, que podríamos tomar como la tercera dimensión de la Justicia de Género. Según Fraser (1996, p. 32), para que exista justicia son necesarios unos "arreglos sociales" que permitan una interacción de igual a igual entre todas las personas adultas. Para lograr esa paridad, se requieren unas reglas de igualdad legal formal, una distribución de la riqueza material que permita la independencia y la voz de todas las personas (precondición objetiva), y unos modelos culturales de interpretación y valoración que permitan el respeto mutuo y aseguren la igualdad de oportunidades para la estimación social (precondición intersubjetiva) (Fraser, 1996, p. 32-33). 
Vemos que la paridad participativa está totalmente relacionada con la redistribución y el reconocimiento. Sin embargo, es interesante pensar en las tres dimensiones para propósitos analíticos. En esta investigación, estas tres dimensiones (redistribución, reconocimiento, participación) han sido centrales para diseccionar las injusticias de género vivenciadas por las mujeres baserritarras.

\section{Metodología}

La presente investigación sigue una metodología cualitativa (Babbie, 2004, p. 370) centrada en un caso de estudio y basada en entrevistas ${ }^{1}$ en profundidad y el análisis documental. La metodología cualitativa ha sido preponderante tanto en la investigación feminista en general como en la geografía rural con perspectiva de género (Baylina, 2004, p. 5). El estudio de caso se ha realizado en el municipio guipuzcoano de Usurbil a partir de una beca de su ayuntamiento (20132015) para el análisis de la realidad de las mujeres baserritarras. Para ello, se llevaron a cabo 29 entrevistas en profundidad con mujeres de diferentes edades. El requisito principal para la elección de las entrevistadas es que tuvieran o hubieran tenido un contacto importante con el caserío productivo (diferenciándolo de los usos meramente residenciales de gran parte de los caseríos actuales). Hay una predominancia de entrevistas a mujeres de más de 45 años dado que el abandono agrario en la zona dificultó la selección de mujeres jóvenes relacionadas con la agricultura. Esto afecta al contenido de la investigación que se centra principalmente en vivencias referidas al periodo 1950-1980. Las entrevistas fueron semi-estructuradas, para guiar el tema de las mismas pero también permitir la riqueza de información de las entrevistas fluidas y libres (Rubin \& Rubin, 1995). Estas entrevistas fueron analizadas siguiendo las pautas de Taylor y Bogdan (1987): transcripción y descubrimiento (lectura en profundidad), codificación (etiquetado de temas y otros códigos, agrupación y análisis) y relativización (volver al contexto original de cada extracto).

Además, se ha desarrollado un análisis documental tanto para ampliar el conocimiento del medio agrario en Usurbil como para profundizar en la reflexión sobre la situación actual y reciente (últimos 70 años) de las mujeres agricultoras en el País Vasco y otras regiones del Norte Global. Para ello, se ha realizado un análisis de contenido de diferentes tipos de documentos y estadísticas referentes al País Vasco, España, algunos países europeos o Estados Unidos. Entre los documentos utilizados en esta investigación tenemos: publicaciones académicas, informes de asociaciones y sindicatos (Hitzez, Alkartasuna, EHNE, CERES), documentos gubernamentales (Ministerio de Medio Ambiente, y Medio Rural y Marino), estadísticas oficiales (INE, Censo Agrario), webs de referencia local (Noaua) o artículos de prensa.

1 El guión de las entrevistas puede ser consultado bajo requerimiento vía e-mail. 


\section{Contexto agrario}

El espacio agrario lleva experimentando profundos cambios durante las últimas décadas y la provisión alimentaria ha experimentado un largo proceso de integración en la organización industrial de la producción, distribución y consumo de alimentos (Delgado, 2010, p. 32). En el mundo occidental y tras la Segunda Guerra Mundial, la industrialización de la agricultura fue derivando en una polarización entre las explotaciones altamente rentables y aquellas no competitivas que se vieron abocadas a la marginalización y progresivo abandono. Las exigencias productivistas han implicado fuertes inversiones de capital para poder rentabilizar una producción agrícola con precios a la baja por la fuerte competencia del mercado liberalizado. Quienes no han podido realizar esas inversiones han desaparecido progresivamente del mapa agrario. En casi todas las áreas rurales europeas, la inversión, los mercados urbanos, la políica agraria común y la industrialización y comercialización han marcado la adaptación agraria (Alberdi, 2009, p. 396). A partir de los años 1980, la economía rural comienza a diversificarse con la entrada de actividades del sector terciario principalmente, complementando y alterando el papel de la agricultura en el medio rural (Guirado et al., 2014, p. 67).

Según Ruiz-Urrestarazu y Galdos-Urrutia (2013, p. 112), en el caso español, desde el inicio de la reestructuración agraria en la década de 1960, el número de explotaciones agrarias ha ido disminuyendo de manera progresiva y continuada. Además, no es un proceso que se haya ido ralentizando, sino que desde el 2000 ha acrecentado su intensidad: en 2009, el $21 \%$ de las explotaciones existentes en 1999 habían sido clausuradas. Este cierre de explotaciones se relaciona, además, con una disminución de la Superficie Agraria Utilizada (SAU) y un aumento de la superficie artificializada y forestal con grandes repercusiones territoriales (Ruiz-Urrestarazu \& Galdos-Urrutia, 2013, p. 123).

En el caso del País Vasco, la disminución de la SAU en el periodo 1999-2009 fue aún más pronunciada, con una bajada del 26 \% (Ruiz-Urrestarazu \& Galdos-Urrutia, 2013, p. 126). Este dato se relaciona con un proceso de desagrarización más largo (Ainz Ibarrondo, 1996). En la vertiente atlántica y en relación al caserío vasco, su declive o transformación en otros usos (caserío-vivienda, agroturismo o la granja agro-ganadera intensiva) ha venido relacionada con la falta de relevo generacional, con el cambio en los intereses y valores, y con los diferentes incentivos económicos y vitales de otras actividades en comparación con la agrícola (Alberdi, 2009, p. 398). Por su parte, los programas de Desarrollo Rural no han buscado tanto promover la rentabilidad de la actividad agraria como mantenerla con fines paisajísticos y diversificarla para la fijación de población rural (Ruiz Urrestarazu et al., 2012; Alberdi, 2001c, p. 8). En el caso de espacios periurbanos como Usurbil, este proceso no ha necesitado de ayudas o programas ya que la diversificación económica se ha desarrollado autónomamente por la cercanía al espacio urbano (Alberdi, 2001c, p. 9). De 
cualquier manera, diferentes investigaciones muestran que la pluriactividad ha ido en detrimento de la agricultura (Alberdi, 2001c, pp. 10 \& 23).

El caserío (baserri en euskera) se define como el tipo de explotación agrícola más habitual en la vertiente cantábrica del País Vasco y que también encontramos en el norte de Navarra, Cantabria, Asturias y León. Históricamente, el caserío ha sido una explotación de pequeño tamaño, territorialmente disperso, organizado familiarmente y regido por el mayorazgo (Alberdi, 2009, p. 395) y que comprendería casa, tierra, ganado y monte (Ainz Ibarrondo, 2001, p. 141). Además de la actividad económico-productiva, el caserío también debe definirse como el escenario de las tareas reproductivas y productivas para el mantenimiento de los miembros del sistema familiar (Mauleón, 2004, p. 4). De cualquier manera, su definición es problemática (Goikoetxea, 1991, p. 101) y su transformación constante. A finales de la década de los 60 se puede datar el final del caserío como espacio de la agricultura tradicional basado en la continuidad (familia) y la austeridad (autosuficiencia) para consolidar el caserío como explotación rentable integrada en el mercado (Mauleón, 1998, p. 111). Durante la primera mitad del siglo XX se dan diversas fases de la crisis del caserío pero con diferenciaciones (Ainz Ibarrondo, 2001, pp. 122-126). En municipios cercanos a la ciudad, el abandono es menor, la especialización láctea se alterna con la especialización hortícola para el abastecimiento de mercados cercanos y el acceso a empleos industriales para algunos miembros de la familia es mayor (Ainz Ibarrondo, 2001, p. 126). Entre 1950 y 1975 se consolida el caserío mixto o industrial a tiempo parcial para desestructurarse en la primera mitad de 1980 (Ainz Ibarrondo, 2001, p. 166). Desde entonces podemos apreciar dos tendencias ya señaladas: el desarrollo de grandes explotaciones modernizadas o baserris con una actividad agraria casi testimonial que, en algunos casos, combinan con actividades terciarias (Ainz lbarrondo 2001, pp. 282-283). La función residencial es la única que prevalece en el caserío postindustrial (Ainz Ibarrondo, 2001, p. 283).

Usurbil (ver Figura 1) forma parte del periurbano de Donostia dentro de la comarca de Donostialdea-Bidasoa (Gipuzkoa) y se encuentra a orillas del río Oria. Es un municipio de orografía escarpada y la campiña vasco-atlántica es su paisaje característico. Los principales usos del suelo rural son las plantaciones forestales, los prados atlánticos, los robledales acidófilos y mixtos, y las huertas y frutales en ese orden de importancia (Eustat, 2007). Su cercanía a Donostia ha influido fuertemente en su dedicación agraria (producción hortícola y ganadera) así como en el devenir de su caserío (bajo despoblamiento por mantenimiento residencial e introducción de actividades terciarias) (Alberdi, 2001c, p. 23). De cualquier manera, el declive agrario ha sido continuo: lo que se inició como un aumento de la pluri-actividad (combinación del trabajo agrario e industrial) ha resultado ser una transición hacia la desagrarización (Etxezarreta, 1984). Si en 1996, solo había 28 caseríos cuya principal actividad económica fuera la agraria (Alberdi, 2001a, p. 15) en 2009, solo se mantenía una dedicación laboral completa en 24 caseríos, siendo sus jefes de explotación 
mayores de 55 años en 18 casos (INE, 2009). Para 2009, el número de cabezas de ganado había descendido notablemente mientras que la producción hortícola aumentaba por la demanda urbana (INE, 2009). Sin embargo, solo había 84 ha dedicadas a la producción de hortalizas, cereales y árboles frutales (INE, 2009). Esta desagrarización ha venido acompañada de un envejecimiento en los caseríos de Usurbil. Con respecto al género, de las 119 explotaciones con algún tipo de actividad agraria, 28 mujeres eran las titulares y 29 las jefas de explotación (INE, 2009).

Figura 1. Ubicación del municipio de Usurbil

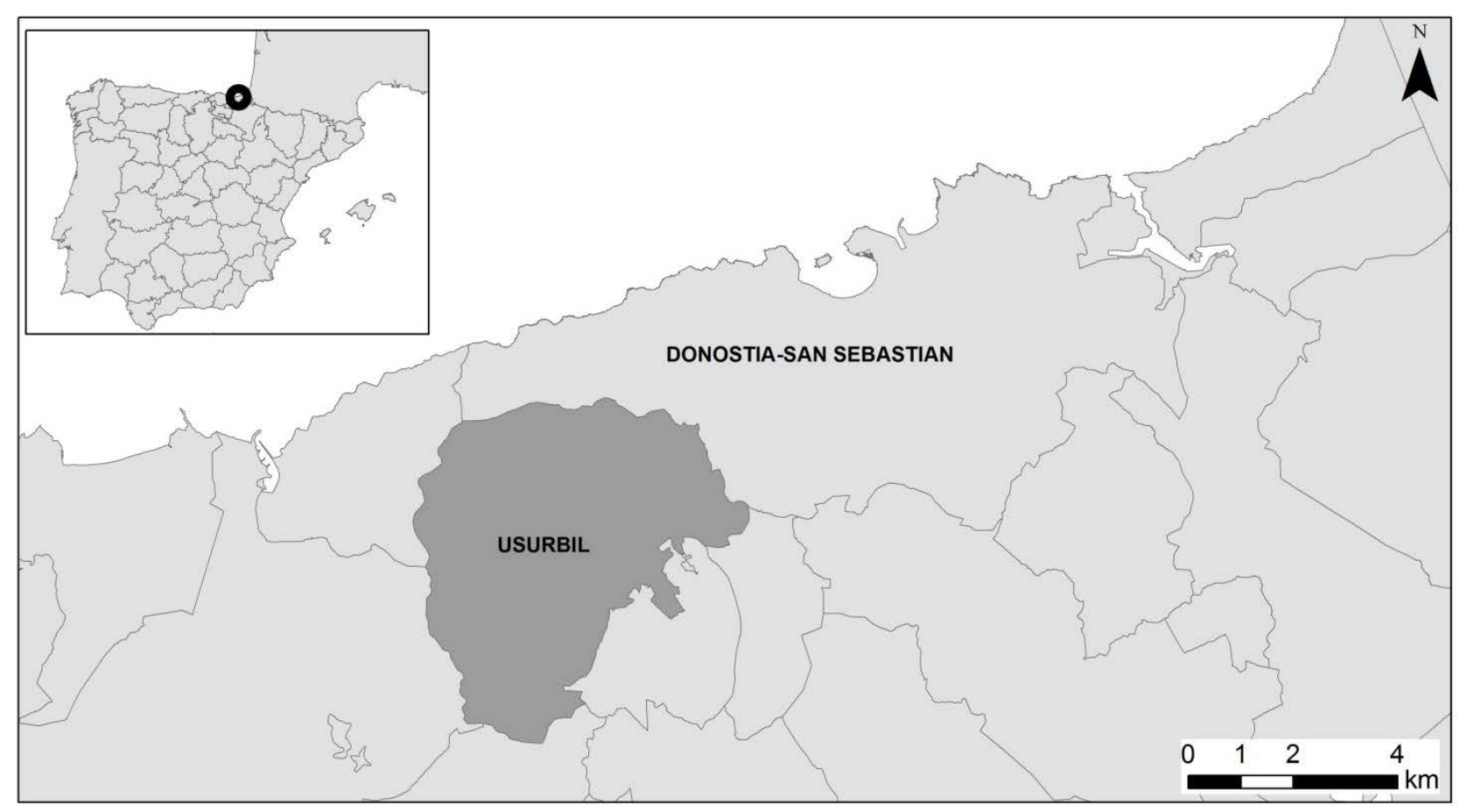

Fuente: elaboración propia

Las transformaciones del sector primario han influido notablemente en la realidad de las mujeres agricultoras en el País Vasco durante las últimas décadas. Estas han implicado un cambio en la división sexual del trabajo y en su valoración. Hay que puntualizar que la división sexual del trabajo que relatamos en este artículo se basa principalmente en la explotación agraria familiar en los últimos 70 años, por ser la principal en el caserío y la vertiente cantábrica del País Vasco y no nos referimos a otro tipo de explotaciones donde la feminización de la precariedad agrícola asalariada se cruza con otras variables de tipo étnico y de procedencia.

\section{Idiosincrasia, vivencias e injusticias vividas por la mujer agricultora}

El grueso del análisis y discusión del artículo lo dedicamos a visibilizar elementos ausentes tanto en la historiografía agrícola como en gran parte de la narración feminista. Nos referimos a la situación, 
idiosincrasia, identidades y relaciones de género y poder de las mujeres en el ámbito agrario. En cada apartado, entrelazamos referencias de estudios europeos, españoles y vascos con las evidencias y testimonios recogidos en Usurbil. Los diferentes subapartados de esta sección se relacionan con las dimensiones de la Justicia de Género que se señalaban en el marco teórico y que comentaremos en las conclusiones.

\subsection{División sexual de trabajo y otras inequidades}

En su análisis de las relaciones de género en la agricultura, la geógrafa feminista Maria Dolors García Ramón (1990, p. 253) cita a Carl Sauer, quien afirmó que las mujeres fueron las inventoras de la agricultura. Todavía hoy, las mujeres son las principales productoras de alimentos en el mundo y, paradójicamente, uno de los colectivos más afectados por la pobreza y discriminación (Escurriol et al., 2014, p. 4). Las mujeres tuvieron un papel crucial en la provisión de alimentos en las sociedades tradicionales - también en las sociedades modernas aunque de otra manera- pero la división sexual del trabajo en la esfera productiva fue muy variada (García Ramón, 1990, pp. 253 \& 257). Esto muestra que la división sexual del trabajo no es algo natural sino que se relaciona con la organización de cada sociedad.

En las sociedades avanzadas, la intensificación y mercantilización de la agricultura ha ido apartando a las mujeres de las tareas vinculadas a los cultivos comerciales, mientras su dedicación a los trabajos domésticos iba aumentando (Escurriol et al., 2014, p. 6). El aumento de escala de las explotaciones, en aras de mantener la rentabilidad en un sistema agroalimentario más globalizado y competitivo, ha afectado al papel de las mujeres en la agricultura: a mayor tamaño de la explotación, menor la participación femenina (García Ramón, 1990, p. 264). En algunos estudios realizados en Estados Unidos, se verifica una relegación de las mujeres a trabajos marginales y a las tareas domésticas o a "ayudar" al marido en las tareas más productivas (García Ramón, 1990, p. 254).

Podríamos decir que en las sociedades capitalistas avanzadas se da una masculinización de la agricultura que propicia mayores inequidades y una emigración de la mujer a la ciudad. Como en muchos otros ámbitos, cuando una actividad toma importancia desde el punto de vista económico o social pasa a ser copada normalmente por hombres (Gasson, 1988, p. 301). Las discriminaciones laborales vinculadas al género se relacionan más frecuentemente con una asignación femenina de trabajos menos valorados social y económicamente que con una discriminación salarial por igual trabajo -que también se da-.

Es importante puntualizar que en la agricultura que se desarrolla dentro de la unidad familiar, la división entre producción y reproducción es difícil de separar, sobre todo para las mujeres. Todo ocurre en el mismo espacio. Es decir, si bien los hombres se dedican casi exclusivamente a las actividades ligadas a los cultivos o ganado comercial, las mujeres transitan entre actividades de 
auto-abastecimiento agro-ganadero, cuidado del hogar y participación en actividades comerciales. Suelen ser ellas quienes cuidan del huerto o del pequeño ganado de autoconsumo que a veces tiene un excedente que venden en mercados locales o en la propia finca. Suelen ser ellas quienes se dedican a la venta y transformación, a pequeña escala, de productos alimenticios tradicionales, al menos en España (Escurriol et al., 2014, p. 7). Son ellas quienes se ocupan de la manutención de los trabajadores agrícolas. Y puede que sean ellas quienes participen en el montaje del regadío o en la alimentación y limpieza del ganado comercial. La mujer realiza muchas tareas del ámbito productivo aunque no se consideren como tal. En un minucioso estudio realizado en Estados Unidos, se demostró que de las doce tareas consultadas, las mujeres participaban asiduamente en un tercio y esporádicamente en más de la mitad (Rosenfeld, 1986, p. 186).

Los discursos que rodean a la agricultura en los países del Norte Global dibujan el trabajo agrícola como una ocupación masculina mientras las mujeres no son agricultoras "serias" (Trauger et al., 2008, p. 434). Estos imaginarios agrícolas están estrechamente relacionados con las imágenes de cuerpos generizados, dado que la agricultura implica trabajar con el cuerpo (Trauger et al., 2008, p. 434). El cuerpo masculino es central, material y simbólicamente, en ese imaginario y el cuerpo femenino es visto como incapaz para la agricultura. Se ve como un cuerpo que "carece" de los atributos masculinos y, por ello, el trabajo desarrollado por las mujeres es valorado como más sencillo y menos valioso (Trauger et al., 2008, p. 434). El cuerpo masculino es el símbolo de la agricultura incluso cuando no es necesaria una labor física (Bryant, 2000).

Dice Barandiaran, en sus obras completas, que, en el País Vasco, de las labores del campo y del establo se ocupaba el hombre, aunque la mujer también participaba en algunas de estas faenas pero siempre "bajo la dirección de aquél" (en Del Valle, 1983, pp. 430-431). También en el ámbito vasco, el hombre ha sido el responsable de las tareas productivas pero la mujer ha trabajado de manera estacionaria e invisibilizada en casi todas las labores del caserío. En el caso de estudio realizado en Usurbil, las mujeres entrevistadas explican que realizaban todo tipo de tareas: participar en la siega de la hierba, realizar los trabajos de la cuadra, cuidar la huerta, recoger colectivamente los productos de temporada (alubia, manzana, maíz), repartir la leche, vender en el mercado, etc. Además de todas los trabajos de cuidados de la casa y de las personas que la habitan. El nivel y tipo de participación de las mujeres en lo productivo difería y difiere de caserío a caserío dependiendo de la composición de la familia y su estructura de género. Sin embargo, su participación como tal es universal en Usurbil.

"[Mis padres] hacen todos los trabajos juntos. $Y$ ahora estoy yo pero, si no estoy, mi madre tiene que poner la comida, la cena y todo" (mujer de menos de 40 años de los caseríos de Usurbil, 2013). 
"La mujer simpre ha sido muy esclava en el caserío, muy esclava. La mujer se levantaba y tenía que hacer los mismos trabajos que el hombre. Porque nosotras hacíamos igual igual que ellos, jeh! Igual igual (...) Y luego venir a casa y, encima, las labores del hogar" (mujer de más de 65 años de los caseríos de Usurbil, 2013).

"Primero los trabajos del establo, luego bajar a repartir y vender la leche y, después, corriendo, a poner la comida. Y por la tarde, si había que trabajar, con el hombre siempre iba la mujer" (mujer de más de 65 años de los caseríos de Usurbil, 2013).

A pesar de reconocer la gran participación de la mujer en las tareas productivas del caserío, muchas perpetúan en sus testimonios la idea de ayudar al hombre. La mujer suele tener un trabajo discontinuo en la agricultura comercial y funciona como comodín cuando conviene dependiendo del ciclo temporal de la explotación (Rico, 2006, p. 20). Volvemos a la idea de "ayuda" que señalábamos y que oscurece toda su aportación, también en Usurbil.

"Las mujeres hacían de todo: la hierba, el ganado, los trabajos de casa, poner las comidas y, luego, ayudar al marido" (mujer de más de 65 años de los caseríos de Usurbil, 2013).

El trabaja femenino no debe amenazar al del hombre (Gasson, 1981) y por eso se verbaliza como "ayuda". Este concepto que está tan arraigado en el ámbito agrícola es una de las mayores perversiones laborales para la mujer: la mujer no trabaja sino que ayuda. Pareciera que no realiza determinadas tareas productivas por una razón mercantil sino por una vocación de ayuda desinteresada al hombre de la familia. De nuevo, el hombre se mueve por la razón (el dinero) y la mujer por la emoción (el amor).

Además, la progresiva tecnificación de la agricultura ha añadido nuevas aristas a la división sexual del trabajo agrario. La tecnificación ha apartado a la mujer de algunas tareas productivas, si bien podría parecer todo lo contrario, dado que los supuestos "impedimentos físicos" de la mujer quedarían anulados gracias a la máquina (García Ramón, 1990, p. 266). Barthez (1982, en García Ramón, 1990 p. 266) documenta cómo la introducción del ordeño mecánico alejó a la mujer de una tarea que solía realizar en Francia. Esto se puede deber al cambio de escala que ocurre en paralelo a la tecnificación o a la equiparación que se realiza entre maquinaria, especialización y masculinidad. En un análisis de los discursos vinculados a los anuncios de tractores, Brandth (1995) descubrió la ausencia de mujeres, ya que "determinadas tecnologías están diseñadas por y para los hombres y presentadas con un lenguaje y simbolismo masculino para marcar un espacio masculino" (Brandth, 1995, p. 133). Según Brandth (1995), la maquinaria agrícola puede entenderse como una extensión del cuerpo masculino y el deseo por equipos poderosos como parte de la fortaleza física. Los discursos actuales sobre la masculinidad rural incluyen claramente narrativas sobre la mecanización y el control de los elementos (Trauger, 2007, p. 290). 
En algunas de las entrevistas de Usurbil, también se documenta la masculinización de la técnica en el caserío, además de la naturalización (o negación contradictoria) de la división sexual del trabajo.

"Mi madre también hacía un montón de trabajo. Andaban los dos; igual si había que utilizar la segadora, lo hacía mi padre pero recogiendo y haciendo las metas andaban los dos. Si había que utilizar las herramientas o el tractor, lo hacía mi padre pero cuidando a los animales más mi madre" (mujer de menos de 40 años de los caseríos de Usurbil, 2013).

"No hay una división del trabajo en relación al género. La mayoría somos chicas. Arreglar los desperfectos y utilizar las máquinas, lo hace mi hermano porque tiene más fuerza. O para limpiar los terrenos, algunas herramientas son más apropiadas para los hombres. ¿Y los trabajos de dentro? Las chicas, siempre las chicas, mi madre y las hermanas. Adaptamos los trabajos a la situación y las capacidades. Como mi hermano tiene más fuerza y genio... (...) No hay una división por el sexo sino por la situación" (mujer de menos de 40 años de los caseríos de Usurbil, 2013).

Otra de las cuestiones clave en la marginación socio-laboral de las mujeres agricultoras se relaciona además con la titularidad de las fincas agrarias y los derechos laborales. Por razones de sucesión u organización patriarcal (Escurriol et al., 2014, p. 6), el titular suele ser el hombre y la mujer aparece en las estadísticas como ayuda familiar. El trabajo de la mujer va a la bolsa común y no le reporta de forma directa ni personal remuneración, derechos sociales ni identidad profesional (Martínez León et al., 2006, p. 12). Esto la sitúa en una posición de dependencia completa ya que no es socia de la explotación (no será compensada si abandona la finca), no cotiza y no tiene derechos laborales (sin cobertura social ni derecho a indemnizaciones por accidente o maternidad y sin acceso a la jubilación contributiva).

Recogiendo datos del censo agrario de 1999, Martínez León et al. (2006, p. 2) señala que, de todas las mujeres que trabajaban en el sector agrario en España, el 29,3\% eran titulares de la explotación, el 42,6\% eran ayudantes y el resto asalariadas (con un alto porcentaje de eventualidad, mayor que en el caso de los hombres). Estos datos esconden la realidad de otras mujeres que se identifican como amas de casa y que aunque colaboren en tareas productivas no se identifican como "ayudantes". En la comarca de Donostialdea-Bidasoa, de las mujeres trabajando en el sector agrario, el 50,6\% eran titulares, el $1 \%$ asalariadas fijas y el $48 \%$ cónyuges u otra ayuda familiar (INE, 2009). De todas las explotaciones censadas, solo en un $31 \%$ de los casos eran mujeres las titulares (INE, 2009).

Una de las históricas reivindicaciones para reconocer el papel de la mujer en agricultura familiar ha sido el establecimiento de la titularidad compartida, ya que es el titular quién recibe las subvenciones y los pagos de la Política Agraria Común, además de ser el representante legal y 
público y estar relacionado con la cotización a la Seguridad Social (De Gonzalo \& Urretabizkaia, 2012, pp. 26 \& 29). En España, después de diferentes iniciativas legales, en 2011 se aprobó la Ley de Titularidad Compartida de las Explotaciones Agrarias. Sindicatos como la COAG pidieron introducir medidas para facilitar la afiliación de las mujeres a la Seguridad Social (si no, no se puede tener la titularidad compartida pero muchas explotaciones no pueden pagar dos cuotas completas de la Seguridad Social, en detrimento de la mujer) y considerar todos los años trabajados, aunque no estuvieran cotizados, para la jubilación (De Gonzalo \& Urretabizkaia, 2012, p. 30). Además, pidieron retirar la obligatoriedad de la comparecencia de ambos cónyuges para pedir la cotitularidad ya que esto podía suponer un obstáculo para las mujeres (De Gonzalo \& Urretabizkaia, 2012, p. 30). Ninguna de estas alegaciones fue aceptada, limitando severamente el desarrollo real de la cotitularidad.

En Usurbil, sí se percibe un mayor reconocimiento laboral de las mujeres agricultoras. El haber comenzado a darse de alta en la seguridad social se identifica como un logro lento pero muy importante para el empoderamiento de las mujeres.

"Todavía falta mucho pero comparando con como era antes... Ahora hay seguridad social y la mujer sí puede estar al frente del caserío. Antes no, antes siempre el hombre, pero hoy en día la mujer también. Todavía queda mucho trabajo por hacer, ¡eh!, queda..." (mujer de entre 45 y 65 años de los caseríos de Usurbil, 2013).

Para finalizar esta sección, nos parece relevante aproximarnos a otra forma de análisis de la división sexual del trabajo, entendiendo el trabajo como toda actividad dedicada a la provisión de bienes y servicios, sea esta realizada en la esfera pública o en la privada y al margen de la existencia de una remuneración o destino (Solsona, 1989, p. 151). Nos referimos a los análisis de uso del tiempo, dado que "lo social es inherentemente temporal" (Legarreta, 2013, p. 1). A pesar de la complejidad del concepto y de la misma percepción temporal, las encuestas de empleo del tiempo ayudan a visibilizar lo ausente en el análisis económico y de cuantificar el volumen de trabajo doméstico (Legarreta, 2013, p. 3). Las encuestas realizadas entre 2009 y 2010 por el Ministerio de Medio Ambiente, Medio Rural y Marino (2011, p. 144) muestran la gran feminización del trabajo doméstico, sobre todo en el medio rural (Tabla 1).

Las mujeres agricultoras suelen dedicar más tiempo al trabajo doméstico y de cuidados que las mujeres con otras dedicaciones, debido a que sus tareas productivas y reproductivas ocurren en el mismo espacio (Escurriol et al., 2014, p. 2), entre otras razones de orden sociológico. Algo que, sin embargo, no ocurre con los hombres agricultores a pesar de que la coincidencia espacial de tareas sería la misma (los hombres rurales dedican 40 minutos menos que los urbanos a las tareas domésticas). Diferentes estudios muestran que la jornada de trabajo (con tareas productivas y reproductivas) es más larga en las mujeres agricultoras que en las urbanas (García Ramón, 1990, 
p. 263). Es la denominada doble jornada femenina, que en el caso de muchas mujeres rurales, llega a ser triple porque trabajan fuera de la explotación agrícola, en la explotación y en el hogar (García Ramón, 1990, p. 267).

Tabla 1. Dedicación diaria a tareas domésticas y de cuidados

\begin{tabular}{|l|c|c|}
\hline Usos del tiempo - Dedicación diaria & Mujeres & Hombres \\
\hline $\begin{array}{l}\text { Media Estatal general - trabajo doméstico (cocina, limpieza de la } \\
\text { casa, limpieza y cuidado de la ropa, compra de productos) }\end{array}$ & $4 \mathrm{~h} 25 \mathrm{~min}$ & $2 \mathrm{~h} 28 \mathrm{~min}$ \\
\hline $\begin{array}{l}\text { Media Rural - trabajo doméstico (cocina, limpieza de la casa, } \\
\text { limpieza y cuidado de la ropa, compra de productos) }\end{array}$ & $5 \mathrm{~h} 38 \mathrm{~min}$ & $1 \mathrm{~h} 48 \mathrm{~min}$ \\
\hline $\begin{array}{l}\text { Media Rural - trabajos de cuidados (cuidado básico de la infancia, } \\
\text { ayuda con los deberes, jugar, cuidado de personas mayores y } \\
\text { dependientes) }\end{array}$ & $5 \mathrm{~h} 39 \mathrm{~m}$ & $3 \mathrm{~h} 40 \mathrm{~m}$ \\
\hline
\end{tabular}

Fuente: MAGRAMA (2011)

Esto repercute en una sobrecarga de trabajo; una de las cuestiones más subrayadas por las mujeres baserritarras de Usurbil.

"Hoy en día, la mujer no tiene más que trabajo en el caserío, dentro y en la huerta. La mujer de la calle [urbanas] tiene más libertad. Comparando con la calle, las de caserío no tenemos ni tiempo libre, ni fiestas, ni vacaciones... A veces digo que no podemos ni enfermarnos. Porque tienes que cuidar a un ser vivo que necesita atención diaria, sino baja la producción" (mujer de menos de 40 años de los caseríos de Usurbil, 2013).

Las tareas de la mujer del caserío vienen entrelazadas y superpuestas: no hay horarios. Además, el escaso reconocimiento de los trabajos de cuidados, aumenta la carga simbólica sobre la mujer, algo también reflejado en los testimonios de las mujeres de Usurbil:

"Antes la mujer era el eje central: para cuidar a los niños, la mujer; para cuidar a los mayores, la mujer; y en los campos, también la mujer" "En el caserío, las mujeres eran quienes cuidaban a los enfermos, los hombres ni caso (...) Y ¿̇reconocimiento? ¡Ninguno!" (mujeres de los caseríos de Usurbil, 2013).

La injusticia en la repartición de las tareas y del descanso queda bien reflejada en esta cita:

"Los hombres de nuestra casa eran egoístas y machistas. Nuestra madre, por ejemplo, venía a la una de repartir la leche y tenía que hacer la comida al momento porque no le gustaba de víspera. Venía nuestro padre, comía y a la siesta corriendo. No miraba por la mujer, no recogía ni el plato de la mesa. La mujer tenía que recoger todo después. Él había echado 20 minutos de siesta pero ella nunca" (mujer de entre 45 y 65 años de los caseríos de Usurbil, 2013). 
Todas estas cuestiones, además de la creciente desagrarización y la dificultad de iniciar proyectos agrícolas, hacen que muchas mujeres jóvenes no quieran involucrarse en la actividad agraria. Algunas mujeres jóvenes de Usurbil que se habían vinculado a la labor productiva a partir de sus cónyuges, señalan que la división sexual y familiar del trabajo había hecho mella en ellas (Usurbil, 2013)

\subsection{Identidades y estereotipos}

En el caserío de Usurbil, la carga de trabajo ha sido el principal rasgo distintivo de las mujeres baserritarras. El saber estar y su carácter continuista a pesar de las dificultades son los rasgos que las entrevistadas recalcan a la hora de definir a la baserritarra. Más allá de conocimientos o valores concretos, la fortaleza que muestran es su principal característica.

"[Las mujeres baserritarras] eran muy sabias. ¡Cuánto sabían! ¡Pero cuánto! A su vez, sabían ser duras. Ellas pasaban muchas muchas horas dentro del caserío, toda la vida. Y la cosa era aprender a estar aquí, a aguantar, a mantenerse aquí. Hoy en día estamos todos mirando hacia fuera, no miramos hacia dentro y nuestro tesoro más preciado está en nuestro interior" (mujer de entre 45 y 65 años de los caseríos de Usurbil, 2013).

"Paciencia. Lo que ha vivido una mujer con el mozo, la tía, la abuela... ¡Hay algunas mujeres! Yo no valdría. Paciencia. Lo aguantaban todo. Las mujeres han hecho mucho trabajo, en muchas áreas, jeh! Iban al mercado, iban al campo, criaban a los niños, cuidaban a los mayores... ¡Son muchas cosas!" (mujer de entre 45 y 65 años de los caseríos de Usurbil, 2013).

Trabajadoras, pacientes, duras... estos son los rasgos destacados en el imaginario sobre la mujer del caserío de Usurbil; virtudes asociadas a la imagen de madre sufridora. Estas cuestiones identificadas en Usurbil se relacionan con una mitificación de la mujer baserritarra vasca y con un conservadurismo enraizado en el mundo rural de manera más generalizada. El mito del matriarcado vasco surge y se reproduce en el contexto del caserío como espacio idealizado y representativo de lo genuinamente vasco (Del Valle, 1999, p. 40). Este mito tan ampliamente extendido en la sociedad se basa en el supuesto poder de la mujer vasca dentro de la estructura familiar, en la relevancia de la diosa Mari, de las brujas y los akelarres en la mitología vasca, en el papel de la mujer en las leyes forales y en determinadas evidencias arqueológicas de dudosa fiabilidad. A nivel teórico y desde diferentes disciplinas, Andrés Ortíz-Osés y Franz-Karl Mayr (1988) y Txema Hornilla (1981) han sido algunos principales defensores de esta tesis en las últimas décadas, siempre basándose en los trabajos de José Miguel de Barandiaran (1974, 1981) y Julio Caro Baroja (1974). 
En los trabajos antropológicos de Barandiaran, la mujer aparece como sostenedora de la familia y la tradición y con un halo mítico-religioso (del Valle 1999, p. 40; Esteban, 2004, p. 73). Siempre aparece en la interacción con sus hijos/as y la afectividad conyugal está ausente. Los estudios etnográficos más recientes sobre el medio rural vasco de William Douglass señalan que, en algunos caseríos, es la mujer la que controla los recursos económicos familiares y que los hombres no tienen capacidad de compra-venta sin el permiso de la mujer (Bullen, 2003, p. 64). Sin embargo, también dice que, en general, la mujer no puede mandar sobre el hombre y que el adulterio es castigado para las mujeres y perdonado para los hombres. Además, Douglass (1977) expone la repartición de tareas en el caserío como parte de una complementariedad mujer-varón, escondiendo las jerarquías subyacentes. Caballero, por su parte, defendió en 1864 que el caserío era una institución paternal, robusta y patriarcal (Berriochoa, 2015, p. 144).

La tesis central del mito matriarcal es que algunos rasgos del supuesto matriarcalismo preindoeuropeo han sobrevivido hasta nuestros días en la sociedad vasca. Esta idea se relaciona con el hecho de que el euskera es una de las pocas lenguas pre-indoeuropeas que se han mantenido hasta la actualidad en el continente (Berriochoa, 2015, p. 144). Según estos autores, la mujer tenía el control de los recursos y del ámbito mágico-religioso en la sociedad vasca paleolítica, al igual que en otras áreas europeas. Caro Baroja, por ejemplo, apoyándose en los trabajos de Estrabón y la escuela de Viena, defiende la existencia de un ciclo agrícola-matriarcal que alcanza hasta inicios del siglo XX en algunos puntos de Europa (Esteban, 2004, p. 72). Sin embargo, la misma tesis sobre la organización matriarcal paleolíica en Europa (antes de las invasiones indoeuropeas) no ha sido aceptada en la investigación arqueológica.

Desde los años 1980, el equipo de la antropóloga Teresa del Valle ha trabajado en la deconstrucción del mito del matriarcado vasco, argumentando que este le ha hecho un flaco favor al movimiento feminista en el País Vasco. Según del Valle et al. (1985) y su Mujer vasca: imagen y realidad, hoy en día, no existe ninguna sociedad matriarcal como tal en el mundo -sí existen organizaciones matrilineales pero no matriarcales- y no hay evidencias de la existencia de la misma en el pasado. Del Valle (1999, p. 40) explica cómo el poder de la mujer vasca es más ideológico que real y se vincula al ideario nacionalista. Esa representación del poder femenino debe entenderse dentro de la construcción de la identidad vasca, en un contexto de opresión cultural (Esteban, 2004, pp. 73 \& 75). La rebeldía, la relación con la naturaleza y la fortaleza de las mujeres son cuestiones identitarias resaltadas en diversos procesos de re-construcción cultural en otras partes del mundo (Esteban, 2004, p. 75). Sin embargo, esa mitificación cultural puede esconder profundas desigualdades de género en la realidad. Además, no es una mitificación que afecte únicamente a un contexto rural hoy en minoría, sino que es generador de identidad en la sociedad vasca en general. Si bien la idea de un matriarcado pasado ha servido a la lucha feminista 
en determinados momentos (Del Valle, 1999, p. 42), la manera en que se conceptualiza en el País Vasco y su supuesta prevalencia le restan potencia para el cambio.

Según Del Valle et al. (1985), algunos de los estudios que sostienen el mito matriarcal confunden carácter con poder y habría que poner en duda el control femenino de la economía del caserío: podrían ser excepciones que llaman la atención, más que generalidades. Además, es interesante observar cómo ese supuesto poder de la mujer vasca se asocia únicamente a su centralidad en la familia y a su papel como mediadora entre el pasado y el presente y la vida y la muerte (Del Valle, 1999, p. 40). En la misma línea, la responsabilidad es otra de las características esperadas en la mujer del caserío y que, al interiorizarse, actúa como delimitadora al hacer que muchas de las acciones de las mujeres no estén impulsadas desde ellas mismas sino desde lo que los demás esperan de ellas (Del Valle, 1983, p. 432).

Por otro lado, la mujer baserritarra ha sido representada como trasmisora de la cultura vasca y salvaguarda de la moral. De hecho, diversos estudios muestran el papel de la mujer en la enseñanza del euskera (aunque los órganos lingüísticos hayan estado casi exclusivamente en manos de hombres) y de la historia oral dentro de la familia, a través de la transmisión de canciones, cuentos, bertsos (poemas tradicionales cantados), leyendas y conocimientos. Así se refleja también en los testimonios de las mujeres de Usurbil:

"Piensa: nuestra madre tuvo 9 hijos e hijas en 15 años y, aunque tuviera trabajo en el caserío, se tomaba su tiempo para sentarse con los críos y contar cuentos viejos o cantar bertsos. ¡¿Con qué paciencia?! O era de otra pasta, o era la época..." (mujer de entre 45 y 65 años de los caseríos de Usurbil, 2013).

Además, la mujer ha tenido un peso central en los ritos de paso y en la relación con los muertos por ejemplo, cuando una mujer se casaba, debía realizar un discreto rito para honrar a los muertos del nuevo caserío (Del Valle, 1983, p. 433)-. En los caseríos de Usurbil hasta los años 60, cuando había un recién nacido se realizaba una reunión femenina llamada atsolorra, donde se preparaba una merienda y las vecinas de otros caseríos acudían con algo de comer para mostrar su protección y compromiso para con la madre y el recién nacido.

“Eso era la reunión que se hacía después de tener familia. Al tener familia, se juntaban todas las mujeres del barrio y se preparaba una merienda. Y solo se juntaban las mujeres" (mujer de más de 65 años de los caseríos de Usurbil, 2013).

Además, de en los ritos de paso, la baserritarra de Usurbil ha jugado un papel central en el mantenimiento de los ritos católicos.

"Para las mujeres baserritarras, la misa ha sido sagrada. Levantarse a las 5, prepararse, coger la farola con la luz -luego salieron las linternas- y ttapa-ttapa-ttapa-ttapa hasta el 
pueblo. Hasta acercarse, iban con las abarcas viejas, totalmente sucias, y al llegar, se limpiaban, se ponían los zapatos y jlistas!" (mujer de entre 45 y 65 años de los caseríos de Usurbil, 2013).

"A la iglesia iban todos, mujeres y hombres. Pero las mujeres le daban más importancia a la religión. Se rezaba el rosario en las casas todos los días, al anochecer. La mujer rezaba y los demás contestaban, estando en la mesa o no" (mujer de más de 65 años de los caseríos de Usurbil, 2013).

El catolicismo ha influido fuertemente en el comportamiento y valores de la mujer vasca y esta ha sido central en el mantenimiento de la religión a pesar de realizar siempre tareas invisibilizadas dentro de la iglesia. Como en otras regiones católicas, la mujer vasca ha sido objeto y sujeto de la defensa de la moral cristiana: ha sido el objeto de tabúes y represiones en relación a su sexualidad, su ocio y su disfrute y también agente activo en la educación moral y en las denuncias moralistas. Todo ello mostrando la doble opresión patriarcal del catolicismo. En las fiestas de Usurbil, mujeres de la cofradía o ayudantes del cura local eran las que vigilaban los bailes y denunciaban a aquellas que se atrevían a trasgredir las normas religiosas:

"Y si bailabas "agarrao", entonces te podían echar de la congregación. La hermana mayor de mi marido es monja y ella decía que una vez que estaba bailando, estaban allí las solteras de Usurbil y le contaron al cura. Entonces, le echaron de la congregación e ¡imagínate qué vergüenza con los padres!" (mujer de más de 65 años de los caseríos de Usurbil, 2013).

La mujer baserritarra será, además, eje cohesionador de la familia y de la comunidad y elemento vinculado a la continuidad frente al cambio. El énfasis en la comunidad puede derivarse de la excesiva importancia dada al rol de madre frente a otros roles e identidades (Del Valle, 1983, p. 430). Todos estos mitos, exigencias y moralidad familiar son parte del pasado pero siguen siendo presente. Y siguen afectando al bienestar, al auto-concepto y a la libertad de las mujeres baserritarras. Precisamente, la opresión del sistema familiar y el rol de las mujeres dentro del mismo hace que algunas mujeres jóvenes rehúsen continuar o entrar al caserío (entrevistas Usurbil, 2013).

Estos estereotipos e idealizaciones señaladas para el caso vasco, también se reproducen en otras regiones aunque con diferentes aristas. $Y$ es que las zonas rurales son a menudo espacios conservadores donde las relaciones de poder y las costumbres cambian lentamente. Obviamente, no son espacios homogéneos ni estancos y las experiencias de resistencias y rebeldías son numerosas. Sin embargo, una encuesta representativa realizada en España a 4.500 habitantes rurales de entre 20 y 65 años muestra que un $25 \%$ de los encuestados cree que hombres y mujeres no pueden realizar las mismas funciones, ni tener las mismas responsabilidades y que un 
$30 \%$ de esta población cree que las mujeres deben sacrificar su faceta productiva, en favor de la reproductiva, y conservar la tradicional atribución de roles (MAGRAMA, 2011).

La mujer rural y agrícola es construida a partir de imágenes tradicionalistas que perpetúan su subordinación (Little \& Panelli, 2003, p. 282). Además, "la construcción de la comunidad en términos de solidaridad y beneficio mutuo, enmascara las consecuencias de la estructura social patriarcal" y limita las oportunidades de cambio (Little \& Panelli, 2003, pp. 282-283). En muchos casos, se espera que las mujeres sean la columna vertebral de las comunidades y la salvaguarda de las tradiciones y de la cohesión social (Hughes, 1997, en Little \& Panelli, 2003, p. 283).

\subsection{Relaciones en el espacio íntimo: poder, aislamiento, resistencias}

Otro de los temas clave en relación al género son las relaciones de poder dentro del hogar y la explotación agraria. Una de las maneras de aproximarse a esas relaciones es el análisis de la toma de decisiones dentro de la familia. Según diversos estudios, las mujeres han tenido una escasa participación en la toma de decisiones agrarias, con la posible excepción de las explotaciones pequeñas (Martínez León et al., 2006, p. 11; García Ramón, 1990, p. 254). Además, estas han tendido a ser más conservadoras con respecto a la tecnificación o al endeudamiento que los hombres.

En una investigación sobre las mujeres agricultoras en España, Leticia Urretabizkaia y Verónica Escurriol (2013, p. 8) resaltan que cuando se comparte la actividad productiva con cónyuges o compañeros, en las negociaciones internas en cuanto a inversiones y tiempos, las mujeres "han de demandar la necesidad de decidir conjuntamente, y en definitiva defender constantemente que lo que ellas opinan y necesitan también es importante". Las mujeres entrevistadas subrayan la relevancia de los roles de género en la toma de decisiones productivas con sus parejas (Escurriol, 2014, p. 15). La dificultad de esas negociaciones y la escasa corresponsabilidad tanto en lo productivo como en lo reproductivo - aunque de maneras diferentes-, hace que muchas mujeres prioricen su papel de cuidadoras (Urretabizkaia \& Escurriol, 2013, p. 8). Esto les lleva a contradicciones y crisis de identidad y les genera malestar por el hecho de tener que salir de un ámbito de toma de decisiones y de acción por el bienestar de sus familias (Urretabizkaia \& Escurriol, 2013, p. 8). Esto no ocurre en proyectos formados solo por mujeres o por una mayoría de mujeres porque el género deja de ser un condicionante central (Escurriol, 2014, p. 15).

La mayor participación de las mujeres en la toma de decisiones llega cuando estas son propietarias o co-propietarias (García Ramón, 1990, p. 254). Precisamente, en un estudio empírico en Eslovenia, Cernic Istenic (2015) señala que la división del trabajo y la toma de decisiones es más igualitaria cuando las mujeres se convierten en gestoras y propietarias de las explotaciones, mostrando la relevancia de la propiedad de la tierra para la igualdad y para la obtención de respeto y estatus profesional por parte de las mujeres. 
Otro tema central en el espacio íntimo son las relaciones de dominación y la violencia machista. Estas situaciones conllevan una mayor complejidad en el medio rural por ser un entorno más reducido y masculinizado (Binimelis et al., 2008, p. 60) y por el peso que en muchos casos se le otorga a la cohesión de la comunidad frente a los derechos individuales. Además, las mujeres tienden a sufrir una mayor dependencia económica en el medio agrícola, dadas las causas que hemos venido explicando. Por ello, por miedo, por vergüenza o por falta de servicios sociales, muchas veces, se esconden trágicas situaciones de violencia machista (Binimelis et al., 2008, p. 60). Por todas estas y otras razones, las mujeres rurales son el grupo que mayores dificultades presentan para salir de relaciones violentas (Sanz, 2011 en Escurriol, 2014, p. 7). Esto también es extrapolable a la realidad de las mujeres agricultoras asalariadas por su gran vulnerabilidad y dependencia, quienes frecuentemente son víctimas de acoso laboral y sexual (Allen \& Sachs, 2007, p. 6).

La tranquilidad de la vida en el caserío es algo destacado por las mujeres de Usurbil pero tiene su parte negativa, dadas las normas generizadas de sociabilidad y movilidad. El aislamiento es algo presente en sus testimonios.

"Muchas mujeres Iloraban y se escondían. ¿Sabes cuál era la siguiente tendencia? Beber. En el caserío, había muchas mujeres que se escondían y bebían, muchas y muchas. ¿Por qué? Porque estaban oprimidas por el hombre. El hombre salía y ella allí" (mujer de entre 45 y 65 años de los caseríos de Usurbil, 2013).

La mejora de caminos y carreteras y el acceso al transporte rodado y a las telecomunicaciones ha alterado esta situación (Murua, 2009, p. 269), pero muchas mujeres siguen resaltando el aislamiento y el silencio como elementos dolorosos que no solo tienen que ver con el espacio, sino también con las normas de género. De hecho, en Gipuzkoa existe una asociación llamada Hitzez cuya principal función es luchar contra el aislamiento de la mujer en la zona rural: organizan salidas y encuentros y ofrecen servicios de atención psico-social. Su nombre viene precisamente de la necesidad de hablar de las mujeres baserritarras.

“La mujer, totalmente oprimida, bajo el yugo del hombre siempre. La mujer empezó a vivir un poco con el transporte y cuando empezó a tener seguridad social y [alta en] agraria... hace 35-40 años la cosa empezó a cambiar (...) pero falta mucho por hacer..." (mujer baserritarra de entre 45 y 65 años de los caseríos de Usurbil, 2013).

Dada la división sexual del trabajo y las relaciones de género, las mujeres baserritarras han vivido, en general, en una situación de dependencia y opresión. Ha habido transformaciones pero hay mucho que avanzar. De cualquier manera y en contra de todas las inercias, las mujeres han sido capaces de construir complicidades, ayudas mutuas, espacios de liberación y "resistencias cotidianas" (Scott, 1987). Las mujeres, como grupo subalterno, han negociado y peleado su 
situación, aunque no fueran peleas abiertas y públicas. Esto muestra cómo, más allá de los roles tradicionales, generación tras generación, ha habido grietas para la rebelión (Juliano, 1992), aunque estas no fueran muy visibles. La participación socio-política siempre se relaciona con el espacio público. Pero, en el ámbito privado, también se dan relaciones y resistencias políticas ("lo personal es político").

Muchas veces se dice que, entre las mujeres, las relaciones son más de competencia que de colaboración. Esto no es esencial sino que los roles de género han construido así la imagen de la mujer. La competencia y enemistad han sido especialmente resaltables y resaltadas en el ámbito de la moral. Sin embargo, más allá del estereotipo, vemos cómo las relaciones de ayuda mutua entre mujeres en el caserío son muy frecuentes. En Usurbil, las mujeres establecieron durante años redes informales de colaboración, especialmente para el cuidado de las criaturas. En un barrio alejado del centro de Usurbil, por ejemplo, tenían un sistema de turnos para llevar a las niñas y niños a la escuela a través de un peligroso túnel del tren.

Los caminos siempre han sido importantes en el mundo del caserío, dada su típica dispersión territorial. Así, en Usurbil, el camino en burro hasta el mercado de Donostia suponía un momento idóneo y exclusivamente femenino para compartir sus problemas, angustias y alegrías y, a pesar de lo abierto, el camino se convertía en espacio íntimo. En algunos barrios más centrales, las mujeres se juntaban en la puerta de un caserío o en la plaza para coser y compartir las preocupaciones y emociones cotidianas. Y dentro del hogar, en algunos casos, las mujeres hacían piña contra los abusos del hombre de la casa, se protegían o le hacían frente (entrevistas Usurbil, 2013). Las mujeres baserritarras han establecido estrategias cotidianas de resistencia a partir de sus complicidades y, a su manera y ritmo, han construido caminos de cambio. Hoy en día, las relaciones de ayuda y apoyo emocional entre mujeres son mayores por el cambio de conciencia y las facilidades de las telecomunicaciones y el transporte, aunque no se ha terminado de romper ese silencio antes comentado (entrevistas Usurbil, 2013).

\subsection{Participación pública}

Otra de las cuestiones que marcan el verdadero escaso poder de la mujer rural vasca es su limitada presencia en el espacio público. En su análisis de 1974 de la mujer de Vera, Caro Baroja dice que "si el hombre casado hace una vida, un poco social, la mujer casada, en cambio, se retrae. Apenas sale más que lo estrictamente necesario, lo que exige el buen mantenimiento de las relaciones y el cumplimiento de los deberes religiosos (...) todo el tiempo lo pasa en el caserío o en el campo trabajando" (Del Valle, 1983, p. 433).

Los hombres participaban más en el auzolan (trabajos comunitarios en el barrio), iban a las sociedades y tabernas, acudían a los mercados a pasear y comprar, etc. Además, el hombre era el representante público del caserío y participaba en sindicatos, asociaciones y actividades 
organizativas (Homobono, 1991, p. 103). Esto también queda reflejado en las entrevistas realizadas en Usurbil en 2013: los ámbitos públicos de la mujer se restringían a misa y al mercado -donde iban a trabajar y no a curiosear o pasear como hacían los hombres en las ferias-. La mujer no tenía gran acceso al espacio público y tampoco al tiempo de ocio, a diferencia de los hombres.

"¿Qué hacía la mujer en su tiempo libre? Trabajar. No existían los domingos. Antes para las fiestas lo que hacíamos era ipintar la casa!". "El trabajo de la mujer baserritarra es continuo, no tiene fin. El hombre tenía sus siestas, sus sociedades, sus ferias. Las mujeres no se juntaban en ninguna parte, nunca paraban su trabajo" (entrevistas a mujeres de los caseríos de Usurbil, 2013).

La presencia de las mujeres rurales en fiestas y espacios de ocio ha aumentado pero su actividad en el espacio público y en la representación social sigue siendo menor. Esto se asocia a un sentimiento de minusvalía y aislamiento que perdura. Una de las entrevistadas en Usurbil nos explicaba cómo de joven tenía que acudir a las reuniones de la cooperativa agraria local por ausencia de hombres en su familia. Su recuerdo de esa experiencia es de discriminación (entrevistas Usurbil, 2013).

Las dobles y triples jornadas de la mujer agricultora y su dedicación a las tareas reproductivas y al cuidado de las personas dependientes limitan su participación en las actividades públicas. A parte del exceso de trabajo, los horarios de reunión en muchos sindicatos, asociaciones o comisiones rurales son incompatibles con el cuidado de terceros. Es el cabeza de familia quien generalmente representa a la familia y a la explotación agraria públicamente y quien participa activamente (Martínez León et al., 2006, p. 13). A nivel europeo, las mujeres están muy subrepresentadas en los programas de formación agrícola y en los sindicatos agrarios (Shortall, 2015, p. 722).

En un estudio realizado en España por la Comisión Europea, se muestra cómo las mujeres rurales tienen una fuerte presencia en las asociaciones culturales, grupos de mujeres y colectivos locales pero su participación política en las estructuras sindicales, cooperativas u organizaciones políticas está muy lejos de una situación paritaria (Binimelis et al., 2008, p. 51). En lo que se refiere a Catalunya, en las elecciones de representantes a las cámaras agrarias de 2007, solo el 11,5 \% de las candidatas fueron mujeres; dato que desciende al analizar la presencia femenina en los órganos de gobierno de los sindicatos agrarios (Binimelis et al., 2008, p. 51). Estos porcentajes se correlacionan también con el escaso o bajo grado de participación de las mujeres como socias en las cooperativas agrarias catalanas (Binimelis et al., 2008, p. 52). En esta investigación ha sido imposible contar con datos de participación femenina en la cooperativa agraria de Usurbil o en los sindicatos agrarios a nivel de Gipuzkoa o País Vasco, ya sea por cuestiones de confidencialidad o por no contar con esa contabilidad (comunicaciones personales, 2017). Sin embargo, se constata una presencia muy baja de mujeres en los sindicatos agrarios vascos (comunicación personal, 
2017); hecho que se viene subsanando mediante la afiliación compartida a nivel familiar también en el sindicato.

Es cierto que la incorporación de la mujer a la vida pública se está dando y que la mujer es vista cada vez más frecuentemente como motor de la dinamización social rural en España (Rico, 2006, p. 2) pero su presencia en la vida pública rural sigue siendo limitada. Según un estudio del Ministerio de Medio Ambiente y Medio Rural y Marino (2011, p. 167), los hombres dedican una hora más a la semana a la participación social y política que las mujeres.

Las organizaciones agrarias y rurales son mayoritariamente masculinas en su composición y sus miembros todavía siguen aferrados a mantener el dominio absoluto y exclusivo de las mismas (Martínez León et al., 2006, p. 13). Además de las largas jornadas laborales de las mujeres agricultoras y la división sexual del trabajo, otra limitación es la fuerte masculinización de los espacios de participación agraria (Binimelis et al., 2008, p. 52). Las mujeres no son reconocidas como agentes activos dentro de estas herméticas organizaciones. $Y$, en consecuencia, muchas mujeres se auto-excluyen por la falta de tiempo, experiencia o confianza (Bock, 2015, p. 737). En un estudio realizado en España, Urretabizkaia y Escurriol (2013:10) señalan la manifestada baja auto-estima de las mujeres agricultoras, dado que no solo son minusvalorados los trabajos que ellas realizan sino también su manera de participar productiva y políticamente. A las barreras de discriminación directa e institucional, hay que añadir las relaciones de género más cotidianas, donde las mujeres no son tratadas con respeto por parte de su propia familia, otros agricultores o profesionales agrícolas (Allen \& Sachs, 2007, pp. 5-7). Los estereotipos de género son muy fuertes, como expresa esta cita de una agricultora extraída de Binimelis et al. (2009, p. 143): "Es un sobreesfuerzo brutal, y más si no vienes del campo. Te miran más el escote en vez de escucharte. Hasta que no te conocen, no te toman en serio".

Las mujeres participan y han participado, sobre todo en el ámbito más local, pero con una tendencia a actividades de segundo plano y sin ocupar puestos públicos o de poder. Prefieren participar en actividades o asociaciones que son percibidas como menos competitivas o más relacionadas con la vida diaria (Bock, 2015, p. 737). Estos colectivos suelen ser poco representativos o poco tomados en cuenta en las políticas rurales o agrícolas, lo que mantiene la exclusión de las mujeres de la esfera más decisoria (Bock, 2015, p. 737). Sin embargo, hay mujeres que rompen con ese silencio impuesto, entran a los espacios de toma de decisión y reivindican la visibilización de las mujeres y sus necesidades específicas más allá del sujeto neutrovarón (Binimelis et al., 2008, pp. 54-57). Estas mujeres tienden a transgredir los roles esperados en las comunidades rurales, enfrentándose al recelo o la marginación (Trauger, 2004 en Trauger et al., 2008, p. 432) o a su propia frustración por las trabas encontradas (Binimelis, et al., 2008, p. 55). 


\section{Conclusiones y notas finales}

A partir del caso concreto de Usurbil y las referencias a estudios de diferentes regiones del Norte Global, este artículo muestra cómo la inequidad de género vivida en el espacio agrario se puede entender desde las tres dimensiones de la Justicia de Género extraídas de las reflexiones de Nancy Fraser (2008, pp. 91-92) y otras teóricas feministas: redistribución, reconocimiento y participación. Las particularidades del espacio agrario analizado (agricultura familiar) hacen que la forma en que estas dimensiones se concretan en la realidad difiera de lo que ocurre en espacios urbanos u otros tipos de explotaciones agrarias.

Como señala la Geografía del Género (Little et al., 1988, p. 2), la división sexual del trabajo es un aspecto central de las injusticias vivenciadas por las mujeres en el espacio agrario. Una de las cuestiones clave de la agricultura familiar es que gran parte de las tareas productivas y reproductivas se desarrollan en el mismo espacio. Esta cuestión, que podría derivar en una mayor igualdad en la división sexual del trabajo, en realidad se ceba con las mujeres y su tiempo. A pesar de que las mujeres participan activamente en las tareas productivas (de muy diferentes formas en cada explotación), su trabajo se infravalora por ser más estacional y marginal y se califica de ayuda (o se considera marginal por ser realizado mayormente por las mujeres). Las tareas reproductivas o de cuidados no se conceptualizan como trabajo y recaen principalmente en las mujeres, con una menor incorporación masculina a las mismas que en el medio urbano. De nuevo, nos encontramos con la misma definición de "trabajo" como una de las piedras angulares del patriarcado (Carrasco, 2009 , p. 3). Además, esta división sexual del trabajo se traduce en una marginación de la mujer con respecto a su identidad laboral oficial y a todos los derechos económicos, laborales y sociales asociados.

De hecho, las desigualdades distributivas están íntimamente relacionadas con las ausencias de reconocimiento. Como señala Fraser (2008, p. 91), el género es una categoría híbrida anclada simultáneamente en la estructura económica y en el orden de estatus de la sociedad. La mujer no es considerada una agricultora real. El cuerpo masculino es el representativo de las características de un cuerpo agrícola. Además, el proceso de mecanización de la agricultura, en vez de propiciar un mayor acceso femenino a los trabajos físicamente muy intensivos, se ha articulado con y ha reforzado la masculinidad más clásica. La mujer rural y agraria es construida a partir de imágenes tradicionalistas $y$, de hecho, las relaciones tradicionales de género son parte constitutiva de la sociedad rural ideal. La mujer es imaginada en relación al cuidado y al mantenimiento de la familia y de la cohesión comunitaria.

Este aspecto es especialmente importante en el País Vasco, donde el imaginario del matriarcado ha construido una mujer fuerte pero dentro de la estructura social clásica: la salvaguarda de la familia, de la moral y de la comunidad. Como hemos señalado, la supervivencia del mito del matriarcado 
responde a cuestiones ideológicas y culturales pero ha tenido un importante peso en la percepción social de la mujer vasca, limitando, en muchos casos, las reivindicaciones feministas. El mito hunde sus raíces en el caserío agrario pero afecta a todo el imaginario de la mujer vasca.

Otra de las cuestiones importantes a la hora de analizar la justicia de género en el espacio agrario es el impacto de su estructura territorial. La dispersión propia del caserío familiar vasco ha sido señalada por muchas mujeres en Usurbil como fuente de aislamiento. A su vez, este aislamiento ha sido relacionado con la incomunicación y con la incapacidad de verbalizar y compartir la represión de la estructura familiar patriarcal. Además, las relaciones de poder dentro de la familia agraria dificultan su participación igualitaria en la toma de decisiones de la explotación agraria, repercutiendo también en la autoestima. A pesar de todo ello, las mujeres han sido capaces de construir complicidades, ayudas mutuas y resistencias cotidianas, contribuyendo al cambio aunque sea de una manera no demasiado pública. En Usurbil, los caminos han simbolizado esos espacios para el encuentro, la resistencia y el avanzar en la transformación cotidiana.

Por último, otra de las aristas que marcan el verdadero escaso poder de la mujer rural vasca es su limitada presencia en el espacio público. Diferentes estudios a nivel estatal muestran que la participación de las mujeres en sindicatos y cooperativas agrarias es muy baja debido a múltiples razones: el exceso de trabajo, los incompatibles horarios de reunión, la equiparación entre titular de la explotación y representante público, la fuerte masculinización de estos espacios, la falta de respeto hacia las mujeres y la auto-exclusión que todo lo anterior implica. Las mujeres siempre han participado en la escena colectiva pero, generalmente, en tareas de segundo plano o en dinámicas alejadas de la toma de decisiones verticales. La dimensión participativa nos sitúa en el cruce de caminos entre el reconocimiento y la distribución: cuando los patrones de falta de respeto se institucionalizan, aparecen las exclusiones participativas en las instituciones, dificultando los cambios en lo normativo y económico (Agarwal, 2001, p. 1623).

La mayoría de las situaciones analizadas en el artículo se remontan a décadas atrás, cuando la actividad agraria estaba más activa en el País Vasco. Las experiencias de las mujeres rurales han ido cambiando para asemejarse cada vez más a la vivencia urbana (Salamaña et al., 2016, p. 678) pero, de cualquier modo, la agricultura sigue siendo un campo lleno de injusticias sociales y de género (De Gonzalo \& Urretabizkaia, 2012). Como alternativa a esta situación, en los últimos años, están emergiendo propuestas agrarias como la Soberanía Alimentaria que reivindican la democratización, también en el eje de género, del sistema agro-alimentario. El discurso de la Soberanía Alimentaria reconoce explícitamente y de manera central el trabajo agrícola de las mujeres, sus conocimientos y sus derechos (Young et al., 2013, p. 2). Además, la Soberanía Alimentaria propone situar la alimentación en el centro de la vida económica, social y política, no como una mercancía, sino como satisfactor clave de necesidades (García Roces et al., 2015, p. 81). Esta propuesta se relaciona con la Economía Feminista, en el sentido de localizar la 
sostenibilidad de la vida en la centralidad de la organización social y económica (García Roces et al., 2015, p. 81). Estas propuestas son interesantes sobre todo cuando se toman desde una perspectiva no-esencialista, entendiendo que no solo es necesario valorar las tareas de cuidados sino colectivizarlas y des-feminizarlas (Herrero, 2013, p. 85); también en lo agro-alimentario.

En la práctica, iniciativas que podemos vincular con el modelo de la Soberanía Alimentaria (a pequeña escala, con circuitos cortos de comercialización y sin grandes insumos químicos) son un nicho laboral para las mujeres, donde tienen tasas de participación, liderazgo y reconocimiento externo más altas (Bizilur \& Etxalde, 2015, p. 27; Urretabizkaia \& Escurriol, 2013, p. 6; Trauger, 2007, pp. 290 \& 300), dado que son actividades más vinculadas a las tareas tradicionalmente relegadas a lo femenino (Trauger, 2007, p. 298). Afirma Alicia Puleo que, actualmente, muchas mujeres encuentran en la agroecología una nueva forma de empoderarse en la familia y en la sociedad (Velasco, 2010, p. 170). Por ello, estas experiencias pueden ser espacios de resistencia donde renegociar las identidades de género: se transforma la imagen de lo que es una persona agricultora y se visibilizan otras identidades de ser mujer (Trauger, 2007, pp. 290 \& 304).

En el País Vasco, el sindicato agrario EHNE ha tenido un papel central en la defensa de la Soberanía Alimentaria y los derechos de las mujeres agricultoras. Las mujeres dentro del movimiento vasco de la Soberanía Alimentaria reclaman poder desarrollar un trabajo digno con plenitud de derechos y subrayan la necesaria simbiosis entre agricultura y feminismo: "ruralizar el feminismo y feminizar el campo" (Bizilur \& Etxalde, 2015, p. 19). Son muchos los obstáculos y riesgos, pero estas alternativas agrarias nos pueden mostrar aprendizajes para avanzar en la despatriarcalización de la agricultura.

Agradecimientos: Este artículo es producto de una beca de investigación financiada por el Ayuntamieto de Usurbil en 2013 y 2014.

Declaración responsable: La autora declara que no existe ningún conflicto de interés en relación a la publicación de este artículo. 


\section{Bibliografía}

Agarwal, B. (2001). Participatory exclusions, community forestry, and gender: an analysis for South

Asia and a conceptual framework. World Development, 29, 1623-1648. doi: http://dx.doi.org/10.1016/S0305-750x(01)00066-3

Ainz Ibarrondo, M. J. (1996). El último proceso de cambio en el territorio del caserío vasco. Lurralde: investigación y espacio, 19, 137-154.

Ainz Ibarrondo, M. J. (2001). El caserío vasco en el país de las industrias. Madrid: Ministerio de Agricultura, Pesca y Alimentación, Centro de Publicaciones.

Alberdi Collantes, J. C. (2001a). Activo envejecido sin recambio generacional en el caserío vasco. Papeles de Geografía, 33, 5-21.

Alberdi Collantes, J. C. (2001b). La ciudad potencia y destruye la actividad hortícola: el periurbano de San Sebastián. Lurralde: investigación y espacio, 24, 77-97.

Alberdi Collantes, J. C. (2001c). De la actividad ganadera a los usos recreativos: el caserío como espacio de ocio. Cuadernos de Turismo, 8, 7-25.

Alberdi Collantes, J. C. (2009). Medio rural y abandono de la agricultura. Desarrollo de un ejemplo: el caserío vasco. Lurralde: investigación y espacio, 32, 395-404.

Etxezarreta, M. (1984). La agricultura a tiempo parcial en Euskadi (Unpublished). Oiartzun.

Allen, P., \& Sachs, C. (2007) Women and Food Chains: The Gendered Politics of Food. International Journal of Sociology of Food and Agriculture, 15(1), 1-23.

Babbie, E. (2004). The Practice of Social Research. Belmont, USA: Wadsworth, Thomson Learning.

Barandiaran, J. M. (1974, 1981). Obras Completas. Bilbao: La Gran Enciclopedia Vasca.

Baylina Ferré, M. (2004). Metodología para el estudio de las mujeres y la sociedad rural. Estudios Geográficos, 254, 5-28. doi: http://dx.doi.org/10.3989/egeogr.2004.i254

Baylina Ferré, M., \& Salamaña Serra, I. (2006). El lugar del género en Geografía Rural. Boletín de la Asociación de Geógrafos Españoles, 41, 99-112. Retrieved from http://www.agegeografia.es/ojs/index.php/bage/article/view/1993/1906

Berriochoa, P. (2015). La baserritarra en el caserío vasco, siglos XIX y XX. In T. M. Ortega López (Ed.), Jornaleras, campesinas y agricultoras. La historia agraria desde una perspectiva de género (pp. 143-160). Zaragoza: SEHA, Prensas de la Universidad de Zaragoza.

Binimelis, R., Bosch, M., \& Herrero, A. (2008). A sol i serena: dones, món rural i pagesia. Barcelona: Institut Català de les dones, Generalitat de Catalunya, pp. 1-80. 
Binimelis, R., Bosch, M., \& Herrero, A. (2009). A sol i serena: mujeres, campesinado y agroecología. In A. Herrero, \& M. Vilella (Eds.), Las mujeres alimentan al mundo: Soberanía Alimentaria en defensa de la vida y el planeta (pp. 136-149). Barcelona: Entrepueblos. Retrieved from http://www.oda-alc.org/documentos/1371488252.pdf

Bizilur \& Etxalde (2015). Sembrando soberanías para otros modelos de vida en Euskal Herria. San Sebastián: Etxalde.

Bock, B. (2015). Gender mainstreaming and rural development policy; the trivialisation of rural gender issues. Gender, Place and Culture, 22(5), 731-745. doi: http://dx.doi.org/10.1080/0966369X.2013.879105

Brandth, B. (1995). Rural masculinity in transition: gender images in tractor advertisements. Journal of Rural Studies, 11, 123-133. doi: http://dx.doi.org/10.1016/0743-0167(95)00007-A

Bryant, L. (2000). The Detraditionalization of occupational identities in farming in South Australia. Sociologia Ruralis, 39(2), 236-261. doi: https://doi.org/10.1111/1467-9523.00104

Bullen, M. (2003). Basque Gender Studies. Reno: University of Nevada Press.

Caro Baroja, J. (1974) [1944]. Estudios Vasco IV: de la vida rural vasca. Donostia: Txerto.

Carrasco, C. (2009). Tiempos y trabajo desde la experiencia femenina. Papeles de Relaciones Ecosociales y Cambio Global, 108, 45-54.

Cernic Istenic, M. (2015). Do rural development programmes promote gender equality on farms? The case of Slovenia. Gender, Place \& Culture: A Journal of Feminist Geography, 22(5), 670684. doi: https://doi.org/10.1080/0966369X.2013.879102

De Gonzalo, I., \& Urretabizkaia, L. (2012). Las mujeres baserritarras. Análisis y perspectivas de futuro desde la Soberanía Alimentaria. Incidencia y políticas públicas en el marco de la actividad agraria y el desarrollo rural. Bilbao: Emakunde.

De Sousa Santos, B. (2006). La Sociología de las Ausencias y la Sociología de las Emergencias: para una ecología de saberes. In B. de Sousa Santos (Ed.), Renovar la teoría crítica y reinventar la emancipación social (encuentros en Buenos Aires) (pp. 13-41). Buenos Aires: CLACSO.

Del Valle, T. (1999). El género en la construcción de la identidad nacionalista. In C. Stallaert (Ed.), Hechos diferenciales y convivencias interétnicas en España (pp. 37-44). Amsterdam: RODOPI.

Del Valle, T. (1983). La mujer vasca a través del análisis del espacio: utilización y significado. Lurralde: Investigación y Espacio, 6, 429-436.

Del Valle, T. (Dir.) (1985). Mujer Vasca, Imagen y realidad. Barcelona: Antrophos. 
Delgado, M. (2010). El sistema agroalimentario globalizado: imperios alimentarios y degradación social y ecológica. Revista de Economía Crítica, 10, 32-61.

Desmarais, A. A. (2003). The Via Campesina: Peasant Women on the Frontiers of Food Sovereignity. Canadian Woman Studies, 23(1), 140-141.

Douglass, W. (1977). Oportunidad y éxodo rural en dos aldeas vascas. Tomos I y II. Auñamendi: Ed. Donostia.

Escurriol Martínez, V., Binimelis, R., \& Rivera-Ferre, M. G. (2014). The situation of rural women in Spain: the case of small-scale artisan food producers. Athenea Digital 14(3), 3-22. doi: http://dx.doi.org/10.5565/rev/athenea.1186

Esteban, M. L. (2004). Zoon andro-ginos: Gizabere arra eta emea, politikan berdin? Uztaro, 48, 61-77.

Eustat (2007). Vegetación de la Comunidad Autónoma del País Vasco 2007. In Lurdata. Retrieved from http://www.eustat.eus/estad/gis_c.html

Fraser, N. (1996). Redistribución y reconocimiento: hacia una visión integrada de justicia del género. Revista Internacional de Filosofía Política, 8, 18-40.

Fraser, N. (2008). La justicia social en la era de la política de identidad: redistribución, reconocimiento y participación. Revista de Trabajo, 6, 83-99.

Gasson, R. (1981). Roles of women on farms: A pilot study. Journal of Agricultural Economics 32(10), 11-20. doi: http://dx.doi.org/10.1111/j.1477-9552.1981.tb01537.x

Gasson, R. (1988). Changing gender roles: a worshop report. Sociologia Ruralis, 28(4), 300305. doi: http://dx.doi.org/10.1111/j.1467-9523.1988.tb00347.x

García Ramón, M. D. (1990). La división sexual del trabajo y el enfoque de género en el estudio de la agricultura de los países desarrollados. Agricultura y Sociedad, 55. 251-277.

García Roces, I., Soler Montiel, M., \& Sabuco i Cantó, A. (2015). Perspectiva ecofeminista de la Soberanía Alimentaria: la Red de Agroecología en la Comunidad Moreno Maia en la Amazonía brasileña. Relaciones Internacionales, 27, 75-96.

Goikoetxea, I. (1991). El caserío vasco: una unidad socio-económica organizadora del territorio rural vasco-atlántico. Boletín de la Asociación de Geógrafos españoles, 13, 101-113.

Guirado, C., Badia Perpinyà, A., Francesc Tulla i Pujol, A., Vera Martín, A., \& Valldeperas Belmonte, N. (2014). La agricultura social en Catalunya: innovación social y dinamización agroecológica para la ocupación de personas en riesgo de exclusión. AGER: Revista de Estudios sobre Despoblación y Desarrollo Rural, 17, 65-97. doi: http://dx.doi.org/10.4422/ager.2014.04 
Harding, S. (1988). ¿Existe un método feminista? In E. Bartra (Ed.), Debates en torno a una metodología feminista (pp. 9-34). México: Universidad Autónoma Metropolitana.

Herrero, Y. (2011). Propuestas feministas para un sistema cargado de deudas. Revista de Economía Crítica, 13, 30-54.

Herrero, Y. (2013). Feminismo y ecología: Reconstruir en verde y violeta. In Medio ambiente y desarrollo. Miradas feministas desde ambos hemisferios (pp. 67-86). Granada: Universidad de Granada.

Homobono, J. I. (1991). Ámbitos culturales, sociabilidad y grupo doméstico en el País Vasco. Revista de Antropología Social, 0, 83-114.

Hornilla, T. (1981). La ginecocracia vasca. Contribución a los estudios sobre el Eusko-Matriarcado. Bilbao: Editorial Greu.

Instituto Nacional de Estadística (INE) (2009). Censo Agrario 2009. Retrieved from http://www.ine.es/CA/Inicio.do

Juliano, D. (1992). El Juego de las Astucias: Mujer y Modelos de Construcción Sociales Alternativos. Madrid: Horas y horas.

Legarreta, M. (2013). El tiempo como herramienta para la economía feminista (una propuesta a partir del estudio del trabajo doméstico y de cuidados). IV Jornadas de Economía Feminista. Retrieved from

http://www.academia.edu/34724605/El_tiempo_como_herramienta_para_la_econom\%C3\%ADa feminista

Little, J., \& Panelli, R. (2003). Gender research in Rural Geography. Gender, Place and Culture, 10(3), 281-289. doi: http://dx.doi.org/10.1080/0966369032000114046

Little, J., Peake, L., \& Richardson, P. (Eds.) (1988). Women in cities: Geography and gender in the urban environment. Basingstoke: MacMillan.

Martínez León, I. M., de Miguel Gómez, M. D., \& Navarro Ríos, M. J. (2006). El papel de las mujeres en las organizaciones rurales y su influencia en el desarrollo rural. Paper presented at the XIII Coloquio de Geografía Rural: Las agriculturas españolas y la política agraria comunitaria: veinte años después. Baeza: Universidad Internacional de Andalucía.

Mauleón, J. R. (1998). Estrategias familiares y cambios productivos del caserío vasco. Bilbao: Servicio Central de Publicaciones del Gobierno Vasco.

Mauleón, J. R. (2004). El Sistema Alimentario como área de estudio para la Sociología. Paper presented at the VI Congreso Vasco de Sociología. Bilbao, February, 26-28. 
Ministerio de Medio Ambiente y Medio Rural y Marino, MAGRAMA (2011). Diagnóstico de la Igualdad de Género en el Medio Rural. Ministerio de Medio Ambiente y Medio Rural y Marino. Madrid: Ministerio de Medio Ambiente y Medio Rural y Marino.

Murua, M. (2009). Vestigios de mundo rural vasco: los casos de Aulesti y Etxalar. Lurralde: cuadernos de investigación y espacio, 32, 253-280.

Ortíz-Osés, A., \& Mayr, F. K. (1988). El Matriarcalismo Vasco. Reinterpretación de la Cultura Vasca. Bilbao: Universidad de Deusto.

Razavi, S. (2003). Introduction: Agrarian Change, Gender and Land Rights. Journal of Agrarian Change, 3(1-2), 2-32. doi: http://dx.doi.org/10.1111/1471-0366.00049

Rico, M. (2006). La mujer y su papel en el desarrollo rural español. Madrid: Ministerio de Agricultura, Alimentación y Medio Ambiente.

Rosenfeld, R. A. (1986). Farm women: farm and family in the United States. London: The University of North Carolina Press.

Rubin, H., \& Rubin, I. (1995). Qualitative interviewing: The art of hearing data. Thousand Oaks, CA: Sage.

Ruiz-Urrestarazu, E., Galdós Urrutia, R., \& Porcal Gonzalo, M. C. (2012). Iniciativas de Desarrollo Rural en las Montañas del País Vasco. Polígonos Revista de Geografía, 18, 123-153. doi: http://dx.doi.org/10.18002/pol.v0i18.201

Ruiz-Urrestarazu, E., \& Galdos-Urrutia, R. (2013). La pérdida de los espacios agrarios, artificialización del suelo y forestación en España y en el País Vasco. Lurralde: investigación y espacio, 36, 121-133.

Salamaña, I., Baylina, M., Garcia Ramon, M. D., Porto, A. M., \& Villarino, M. (2016). Dones, trajectòries de vida i noves ruralitats. Documents d'Anàlisi Geogràfica, 62(3), 661-681.

Scott, J. C. (1985). Weapons of the weak: Every Forms of Peasant Resistance. New Haven: Yale University Press.

Serret, E. (1999). Hermenéutica y feminismo. Por qué es interdisciplinaria la teoría de género. Revista IZTAPALAPA, 45, 17-26.

Shortall, S. (2015). Gender mainstreaming and the Common Agricultural Policy. Gender, Place \& Culture: A Journal of Feminist Geography, 22(5), 717-730. doi: http://dx.doi.org/10.1080/0966369X.2014.939147

Soler, M., \& Pérez, D. (2015). Repensando la alimentación desde la agroecología y el ecofeminismo. In A. H. Puleo, G. A. Tapia González, L. Torres San Miguel, \& A. Velasco Sesma (Coords.), Hacia una cultura de la sostenibilidad. Análisis y propuestas desde la perspectiva de 
género (pp. 367-375). Valladolid: Departamento de Filosofía de la Universidad de Valladolid. Retrieved from hittps://observatorio.aguayvida.org.mx/media/hacia-una-cultura-de-lasostenibilidad.pdf

Solsona, M. (1989). El problema de la medición del trabajo de la mujer. Documents d'analisi geográfica, 14, 149-169.

Taylor, S. J., \& Bogdan, R. (1987). Introducción a los métodos cualitativos de investigación. Barcelona: Paidós.

Trauger, A. (2007). Because they can do the work': women farmers in sustainable agriculture in Pennsylvania, USA. Gender, Place \& Culture: A Journal of Feminist Geography, 11(2), 289-307. doi: hitp://dx.doi.org/10.1080/0966369042000218491

Trauger, A., Sachs, C., Barbercheck, M., Kiernan, N. E., Brasier,K., \& Findeis, J. (2008). Agricultural Education: Gender Identity and Knowledge Exchange. Journal of Rural Studies, 24, 432-439. doi: http://dx.doi.org/10.1016/i.jpurstud.2008.03.007

Urretabizkaia, L., \& Escurriol, V. (2013). Soberanía Alimentaria Feminista: Protagonismo vs. Discriminación de las mujeres del entorno agrario. Paper presented at the IV Congreso de Economía Feminista. Carmona, October, 3-5.

Young, C. M., Ben White, \& Julia (2013). We Are Not All the Same: Taking Gender Seriously in Food Sovereignty Discourse. Paper presented at the International Conference on Food Sovereignty: A Critical Dialogue, Yale University.

Young, I. (1990). Justice and the Politics of Difference. Princeton, NY: Princeton University Press. 